\title{
THE
}

$10-2020$

\section{The High Persistence of PFAS is Sufficient for Their Management as a Chemical Class}

\author{
Ian T. Cousins \\ Jamie C. DeWitt \\ Juliane Glüge \\ Gretta Goldenman \\ Dorte Herzke
}

See next page for additional authors

Follow this and additional works at: https://digitalcommons.uri.edu/gsofacpubs

Creative Commons License

cc) (i) (8)

This work is licensed under a Creative Commons Attribution-Noncommercial 3.0 License

Citation/Publisher Attribution

Environ. Sci.: Processes Impacts, 2020, 22, 2307. https://doi.org/10.1039/D0EM00355G

This Article is brought to you for free and open access by the Graduate School of Oceanography at DigitalCommons@URI. It has been accepted for inclusion in Graduate School of Oceanography Faculty Publications by an authorized administrator of DigitalCommons@URI. For more information, please contact digitalcommons-group@uri.edu. 


\section{Authors}

Ian T. Cousins, Jamie C. DeWitt, Juliane Glüge, Gretta Goldenman, Dorte Herzke, Rainer Lohmann, Carla A. $\mathrm{Ng}$, Martin Scheringer, and Zhanyun Wang 
Check for updates

Cite this: Environ. Sci.: Processes Impacts, 2020, 22, 2307

Received 18th August 2020

Accepted 29th October 2020

DOI: $10.1039 / \mathrm{d} 0 \mathrm{em} 00355 \mathrm{~g}$

rsc.li/espi

\section{The high persistence of PFAS is sufficient for their management as a chemical class}

\author{
Ian T. Cousins, (D)*a Jamie C. DeWitt, Juliane Glüge, (D) C Gretta Goldenman, ${ }^{d}$ \\ Dorte Herzke, ${ }^{\text {ef }}$ Rainer Lohmann, (D) ${ }^{g}$ Carla A. Ng, (D) h Martin Scheringer (D) ${ }^{c}$ \\ and Zhanyun Wangi
}

Per- and polyfluoroalkyl substances (PFAS) are a class of synthetic organic substances with diverse structures, properties, uses, bioaccumulation potentials and toxicities. Despite this high diversity, all PFAS are alike in that they contain perfluoroalkyl moieties that are extremely resistant to environmental and metabolic degradation. The vast majority of PFAS are therefore either non-degradable or transform ultimately into stable terminal transformation products (which are still PFAS). Under the European chemicals regulation this classifies PFAS as very persistent substances (VP). We argue that this high persistence is sufficient concern for their management as a chemical class, and for all "non-essential" uses of PFAS to be phased out. The continual release of highly persistent PFAS will result in increasing concentrations and increasing probabilities of the occurrence of known and unknown effects. Once adverse effects are identified, the exposure and associated effects will not be easily reversible. Reversing PFAS contamination will be technically challenging, energy intensive, and costly for society, as is evident in the efforts to remove PFAS from contaminated land and drinking water sources.

\section{Environmental significance}

Recent scientific publications and regulatory actions suggest that PFAS should be managed as a class. This Perspective article supports a broad scope in restricting the use of PFAS in society based on the extremely high environmental persistence of all PFAS. Our previous work (cited below) has highlighted the particular concern of high environmental persistence and noted that high persistence is the root cause of most of the serious cases of environmental contamination in the last 50 years. The field of green chemistry also recognizes the particular issue with persistence and recommends that chemical manufacturers incorporate "design for degradation". We are of the opinion that highly persistent PFAS are incompatible with green chemistry principles and future visions of sustainable development. Phasing out "non-essential" uses of PFAS from society and replacing them with suitable alternatives will benefit environmental and human health, now and into the future. Unfortunately, as PFAS are non-mineralizable, a reduction of environmental exposure to PFAS will be a slow process even if their uses are phased out.

\section{Perspective article}

The national authorities of five European states have agreed to prepare a joint REACH restriction proposal to limit the risks to

${ }^{a}$ Department of Environmental Science, Stockholm University, SE-10691 Stockholm, Sweden.E-mail: ian.cousins@aces.su.se

${ }^{b}$ East Carolina University, Greenville, NC, USA

'Institute of Biogeochemistry and Pollutant Dynamics, ETH Zürich, 8092 Zürich, Switzerland

${ }^{d}$ Milieu Consulting SPRL, Brussels, Belgium

${ }^{e}$ Norwegian Institute for Air Research (NILU), Fram Centre, N-9296 Tromsø, Norway ${ }^{{ }^{I}}$ Institute for Arctic and Marine Biology, UiT The Arctic University of Norway, N-9037 Tromsø, Norway

${ }^{g}$ Graduate School of Oceanography, University of Rhode Island, Narragansett, RI 02882, USA

${ }^{h}$ Department of Civil \& Environmental Engineering and Environmental and Occupational Health, University of Pittsburgh, Pittsburgh, PA, USA

${ }^{i}$ Chair of Ecological Systems Design, Institute of Environmental Engineering, ETH Zürich, 8093 Zürich, Switzerland human and environmental health associated with per- and polyfluoroalkyl substances (PFAS). ${ }^{1}$ The exact scope of the restriction proposal for PFAS will be determined during the development phase of the project, but it will initially aim for a broad inclusion of substances (the aim is to include "substances that contain at least one aliphatic $-\mathrm{CF}_{2}-$ or $-\mathrm{CF}_{3}$ element") ${ }^{2}$ and uses to be restricted. A recent commentary by Kwiatkowski et $a .^{3}$ outlined the scientific basis for managing PFAS as a chemical class. This was an important contribution towards efforts to regulate $^{4,5}$ and group ${ }^{6,7}$ PFAS. In this Perspective article, we would like to voice our support for a broad scope in the restriction proposal for PFAS, based largely on concerns regarding their high persistence. A precedent for this exists in the recent action by the European Union (EU) to restrict intentionally added microplastics based largely on concerns regarding their high persistence. ${ }^{8}$

PFAS are a class of fluorinated synthetic organic substances with diverse properties that have been used in a wide variety of industrial and consumer applications. ${ }^{6,9}$ The Organisation for 
Economic Co-operation and Development (OECD)/United Nations Environment Programme (UNEP) compiled a list of PFAS with over 4700 CAS numbers that may have been on the global market. ${ }^{\mathbf{1 0}}$ More recently, the United States Environmental Protection Agency (US EPA) ${ }^{\mathbf{1 1}}$ has compiled a list of more than 8000 PFAS entries. ${ }^{12,13}$ As noted in the Supplement to the recent paper by Johnson et al., ${ }^{\mathbf{1 4}}$ the PFAS class comprises distinct substances with very different structures and properties: highmolecular-weight polymers and high-molecular-weight nonpolymers; neutral, anionic, cationic and zwitterionic substances; solids, liquids, and gases; highly reactive and nonreactive (inert) substances; soluble and insoluble substances; and volatile and involatile substances. In the environment, some PFAS are mobile ${ }^{15}$ and others immobile, and some bioaccumulate while others do not.

PFAS display a wide range of environmental and human health hazards. Some PFAS are considered of low health concern (e.g., certain fluoropolymers, ${ }^{\mathbf{1 6}}$ perfluoroalkanes ${ }^{\mathbf{1 7}}$ and perfluoroalkyl-tert-amines $\left.{ }^{3,17}\right)$, whereas others (e.g. long-chain perfluoroalkyl carboxylic (PFCAs) and perfluoroalkane sulfonic (PFSAs) acids) are associated with adverse health effects in humans and wildlife at current environmental exposure levels. ${ }^{18}$ Other PFAS that are structurally similar to PFCAs and PFSAs (e.g. the perfluoroalkylether carboxylic (PFECAs) and sulfonic acids (PFESAs), perfluoroalkyl dicarboxylic acids (PFdiCAs), perfluoroalkyl phosphonic (PFPAs) and phosphinic acids (PFPiAs) and perfluoroalkane sulfinic acids (PFSiAs)) with similarly long perfluoroalkyl(ether) chains to long-chain PFCAs and PFSAs are expected to be of equivalent concern. ${ }^{7,19}$ Even if some PFAS are considered of low health concern, there may be starting materials, breakdown products and/or other PFAS by-products of higher concern released during their lifecycle (e.g. in the case of certain fluoropolymers ${ }^{20}$ ) or they may be of high climate/ environmental concern (e.g. in the case of perfluoroalkanes ${ }^{21}$ and perfluoro-tert-amines ${ }^{22}$ ).

It must be noted that our current understanding of PFAS toxicity and other hazards is based on a relatively small number of compounds, and little is known about the properties and behaviour of most of the thousands of PFAS as individual chemicals or as the much more commonly present complex mixtures. It is likely that additional environmental and human health concerns will be identified as research continues into this class of chemicals. ${ }^{19}$ New findings will undoubtedly be made in toxicology that will change the current hazard and risk perspective of certain PFAS. For example, over the last two decades advances in the understanding of the human toxicology of perfluorooctanoic acid (PFOA) has caused US state level drinking water guidelines to be steadily lowered (from $100000 \mathrm{ng} \mathrm{L^{-1 }}$ in West Virginia in 2002 down to $10 \mathrm{ng} \mathrm{\textrm {L } ^ { - 1 }}$ in multiple states in 2019). ${ }^{23}$

The diversity in PFAS structures, properties and behaviour is often used by the PFAS manufacturing industry ${ }^{24,25}$ to argue that PFAS cannot be treated as a single class. We acknowledge the diversity of PFAS in terms of properties, behaviour, hazards and risks, and that statements such as "all PFAS are bioaccumulative and toxic" are overgeneralized and debatable. However, despite their diversity, PFAS do share one common structural feature that makes them highly problematic, namely the presence of perfluoroalkyl moieties, resulting in their shared resistance to environmental and metabolic degradation. ${ }^{19}$ The vast majority of PFAS are either non-degradable or degrade to form terminal products which are still PFAS (e.g. n:2 fluorotelomer alcohols - $\mathrm{C}_{n} \mathrm{~F}_{2 n+1} \mathrm{CH}_{2} \mathrm{CH}_{2} \mathrm{OH}$ - degrade ultimately to perfluoroalkyl carboxylic acids $\left.-\mathrm{C}_{n} \mathrm{~F}_{2 n+1} \mathrm{COOH}\right) .{ }^{19}$ The extreme resistance to degradation of the perfluoroalkyl moiety is due to: (i) the strength of the $\mathrm{C}-\mathrm{F}$ bond, which is the strongest single bond in organic chemistry, ${ }^{26}$ (ii) multiple $\mathrm{C}-\mathrm{F}$ bonds ("perfluorination") on the same geminal carbon, leading to the shortening (i.e., increased strength) of the $\mathrm{C}-\mathrm{F}$ bond, ${ }^{26}$ (iii) the strength of the $\mathrm{C}-\mathrm{F}$ bond and high electronegativity of fluorine prevents nucleophilic attack ${ }^{\mathbf{2 6}}$ and (iv) the strong electron withdrawing effect of the fluorines in perfluoroalkyl moieties also strengthens the skeletal bonds in the carbon chain. ${ }^{27}$ For example, the $\mathrm{C}-\mathrm{C}$ bond in hexafluoroethane is $29 \mathrm{~kJ} \mathrm{~mol}^{-1}$ stronger than that in ethane. ${ }^{28}$ The high stability of perfluoroalkyl moieties is the reason that many of the applications of PFAS are for uses in high temperature and/or corrosive environments. $^{27}$

The phrasing "the vast majority of PFAS can be classified as highly persistent" was used in the preceding paragraph because there are a few specific structural combinations that may result in specific groups of PFAS that are mineralizable. Merck, for example, have published a patent ${ }^{29}$ for structural combinations of novel fluorosurfactants that they believe may lead to the development of biodegradable commercial products. In this patent, ${ }^{29}$ multiple structural combinations are included that contain per- and polyfluoroalkyl moieties connected to a heteroatom, namely $\mathrm{O}, \mathrm{S}$ or $\mathrm{N}$ (i.e., end groups such as $\mathrm{CF}_{3} \mathrm{O}$, $\left(\mathrm{CF}_{3}\right)_{2} \mathrm{~N}, \mathrm{CF}_{3} \mathrm{~S}$, and many more). To date, only the novel fluorosurfactant 10-(trifluoromethoxy)decane-1-sulfonate, which is a PFAS, has been shown to be mineralizable. ${ }^{30}$ Furthermore, independent of Merck's efforts, a novel fluorosurfactant, 3hydroxy-2-(trifluoromethyl)propanoic acid, ${ }^{\mathbf{3 1}}$ developed for the emulsion polymerization of vinylidene fluoride (VDF) has also been reported to be easily degradable. It is emphasized that these structural combinations that result in non-persistent PFAS are rare.

Environmental persistence is often expressed by half-lives of a chemical in various environmental media based on the kinetics of dominant abiotic and biotic degradation processes. ${ }^{32}$ Although the concept of environmental persistence is simple to understand, its assessment for a given chemical in a given environmental medium can sometimes be a challenging task because of the difficulty in measuring and estimating environmental degradation half-lives for chemicals. ${ }^{33}$ But this challenge does not exist in the case of PFAS because scientists have reached consensus that the vast majority of PFAS are resistant to complete mineralization under natural conditions. ${ }^{19}$ Indeed, to our knowledge, PFAS are the most environmentally persistent substances among organic chemicals, and have thus earned the moniker in the popular press of "forever chemicals". ${ }^{34}$ Therefore, under the REACH definition of persistence, which includes persistent transformation products, the vast majority of PFAS are very persistent (vP). ${ }^{35}$ Unfortunately, not all jurisdictions 
include persistent transformation products in their definition of persistence, and this has given the manufacturing industry some basis to claim that not all PFAS are persistent by neglecting their transformation products.

In a recent paper by Cousins et al., ${ }^{36}$ the concerns regarding the high persistence of chemicals were explained. In summary, these concerns are:

- The continuous release of highly persistent chemicals will necessarily lead to widespread, long-lasting, and increasing contamination.

- Increasing concentrations will result in increased exposures and therefore increased probabilities for known and unknown health effects, be it by individual PFAS and/or in a mixture with other substances.

- Once adverse effects are identified, it will be technically challenging, energy intensive, and thus costly, to reverse the chemical contamination and therefore effects. Even with extensive efforts, removal will be only partially effective, and some level of contamination and some adverse effects will be irreversible.

It was argued by Cousins et al. ${ }^{36}$ that high persistence alone should be established as a sufficient basis for management of a chemical, which was termed the "P-sufficient approach". Logic dictates that evidence of bioaccumulation or some type of effect (biological or otherwise) is not required, given that the occurrence of an effect is of increasing probability and ultimately inevitable if emissions continue. Using current technology, it is not feasible to develop full hazard profiles for all PFAS. Managing these compounds as a highly persistent class is a clear benefit to society because otherwise a large number of resource-intensive and time-consuming toxicity and other tests would need to be conducted. On the basis of plausible reasoning, for continually released, highly persistent organic chemicals, a harmful effect (known or unknown) is likely in the future based on ever expanding exposures. This view may be controversial for some. For example, major regulatory bodies such as the US EPA are instead following the traditional risk assessment paradigm of testing as many PFAS as possible for adverse effects. Because traditional animal testing is costly and considered unethical, the US EPA is instead conducting a large number of high-throughput toxicity tests (in vitro assays) on 150 novel and emerging PFAS for multiple endpoints. ${ }^{37}$ Such approaches are, however, uncertain and not comprehensive in their coverage of chemical or biological space and are not, therefore, reliably protective of human and environmental health. A preventative approach of not using highly persistent synthetic organic substances is more protective and also overall less costly for society, both in terms of fewer tests and reduction in externalized societal costs including the expected costs of health care, loss of biodiversity, loss of ecosystem services, loss of property value and remediation.

The arguments for not using highly persistent organic chemicals in society are not new and have been made for nearly 50 years, early on by Jensen in $1972^{38}$ and Stephenson in $1977^{39}$ and reformulated later in concepts such as "late lessons from early warnings", "planetary boundary threats from chemical pollution," ${ }^{4-43}$ "poor reversibility" of exposure for persistent pollutants ${ }^{44,45}$ and recently in the "P-sufficient approach". ${ }^{36}$ As well as not being new, the arguments have always been simple to understand for scientists and non-scientists alike, and have never been convincingly challenged. Arguments against the "Psufficient" approach often point to inert substances such as some inorganic minerals that are also highly persistent and often in a non-bioaccessible form (e.g. sand and rocks). However, apart from their similar high persistence, PFAS are distinct from inert inorganic minerals in that PFAS (i) are synthetic organic substances and not naturally present (ii) continue to be manufactured, leading to ongoing accumulation in the environment, and (iii) are often bioaccessible. It is noteworthy that only about 20 biogenic organofluorine substances have been identified and PFAS are not among those listed. ${ }^{46}$ Muir et $a l .{ }^{47}$ speculate that the substantial quantities of trifluoroacetic acid found in the deep ocean (estimate of 63 to 187 million tonnes) originate from deep-sea vents (i.e. a geogenic source), but this has not been proven.

There are finally encouraging signs that regulators are taking notice of the problems with high persistence (e.g. in the case of intentionally added microplastics) and that the European Green Deal will hopefully introduce regulatory provisions for highly persistent substances. It is further encouraging that in recent years concepts such as "green chemistry" 48 and "cradle-tocradle" ${ }^{\prime 9}$ are gaining momentum. For example, one of the 12 principles of green chemistry is: "design for degradation", ${ }^{48}$ i.e. chemical products should be designed so that at the end of their function they break down into innocuous transformation products and do not persist in the environment. Highly persistent substances such as PFAS are incompatible with green chemistry principles and future visions of sustainable development (e.g. the European Green Deal). The concept of essentiality has been put forward as a tool for guiding the phase-out of hazardous substances such as PFAS ${ }^{50}$ and efforts have already begun to address this challenging, but not insurmountable, task in the EU and elsewhere. We are of the opinion that the EU restriction proposal $^{1}$ for PFAS should have a wide scope grounded in the one completely consistent feature of PFAS: their persistence, based on the arguments presented in this Perspective article.

Regulation alone is not sufficient to phase out PFAS. Innovation will also be needed by chemical and product manufacturers to develop safer chemical alternatives to PFAS and technological innovation that would make the function obsolete or the use of PFAS unnecessary. There is cause to be optimistic about the future, given the innovations and changes implemented in recent years (e.g. the transition to fluorine-free aqueous film-forming foams in South Australia ${ }^{51}$ and elsewhere, the wider availability of fluorine-free durable water repellent outdoor equipment, ${ }^{52}$ the banning of fluorinated ski waxes in international competition, ${ }^{53}$ the phasing out of PFAS in cosmetics by multiple retailers,${ }^{54}$ the banning of PFAS in paper and board used in food contact materials in Denmark ${ }^{55}$ ), but the work is far from finished.

In summary, although PFAS have diverse structures and behaviour, the high persistence of PFAS is sufficient cause of concern for all "non-essential" uses of PFAS to be phased out. 
Unfortunately, there has until very recently been no legal precedent in any jurisdiction for regulation on high persistence alone. Promisingly, the idea of regulating highly persistent chemicals and intentionally added microplastics is being explored within the EU. We hope that this idea will spread around the world.

\section{Conflicts of interest}

There are no conflicts of interest to declare.

\section{Acknowledgements}

The authors thank the Global PFAS Science Panel (GPSP) and the Tides Foundation for supporting this cooperation (grant 1806-52683). The authors appreciate the valuable suggestions of Mark Miller and Xenia Trier. In addition, Rainer Lohmann acknowledges funding from the US National Institute of Environmental Health Sciences (grant P42ES027706); Jamie DeWitt from the US Environmental Protection Agency (83948101), the US National Institute of Environmental Health Sciences (1P43ES031009-01) and the North Carolina Policy Collaboratory; Carla $\mathrm{Ng}$ from the National Science Foundation (grant 1845336), Dorte Herzke thanks the Norwegian Strategic Institute Program, granted by the Norwegian Research Council "Arctic, the herald of Chemical Substances of Environmental Concern, CleanArctic”, (117031), and Juliane Glüge acknowledges funding from the Swiss Federal Office for the Environment.

\section{References}

1 ECHA European Chemicals Agency, Five European states call for evidence on broad PFAS restriction, accessed 03-07-2020, https://echa.europa.eu/sv/-/five-european-states-call-forevidence-on-broad-pfas-restriction\#: :text=The $\%$ 20national\%20authorities\%20of\%20Germany,PFAS)\% 20by\%2031\%20July\%202020.

2 Information document accompanying the call for evidence supporting an analysis of restriction options for the PFAS group of substances (fluorinated substance(s)), accessed: 05-08-2020, available at: https://www.reach-clp-biozidhelpdesk.de/SharedDocs/Downloads/DE/REACH/Verfahren/ PFAS_RMOA_Supplementary_document.html.

3 C. F. Kwiatkowski, D. Q. Andrews, L. S. Birnbaum, T. A. Bruton, J. C. DeWitt, D. R. U. Knappe, M. V. Maffini, M. F. Miller, K. E. Pelch, A. Reade, A. Soehl, X. Trier, M. Venier, C. C. Wagner, Z. Wang and A. Blum, Scientific Basis for Managing PFAS as a Chemical Class, Environ. Sci. Technol. Lett., 2020, 7(8), 532-543.

4 A. Blum, S. A. Balan, M. Scheringer, X. Trier, G. Goldenman, I. T. Cousins, M. Diamond, T. Fletcher, C. Higgins, A. E. Lindeman, G. Peaslee, P. de Voogt, Z. Wang and R. Weber, The Madrid Statement on Poly- and Perfluoroalkyl Substances (PFASs), Environ. Health Perspect., 2015, 123, A107-A111.
5 A. Ritscher, Z. Y. Wang, M. Scheringer, J. M. Boucher, L. Ahrens, U. Berger, S. Bintein, S. K. Bopp, D. Borg, A. M. Buser, I. Cousins, J. DeWitt, T. Fletcher, C. Green, D. Herzke, C. Higgins, J. Huang, H. Hung, T. Knepper, C. S. Lau, E. Leinala, A. B. Lindstrom, J. X. Liu, M. Miller, K. Ohno, N. Perkola, Y. L. Shi, L. S. Haug, X. Trier, S. Valsecchi, K. van der Jagt and L. Vierke, Zurich Statement on Future Actions on Per - and Polyfluoroalkyl Substances (PFASs), Environ. Health Perspect., 2018, 126, 5.

6 J. Glüge, M. Scheringer, I. T. Cousins, J. C. DeWitt, G. Goldenman, D. Herzke, A. B. Lindstrom, R. Lohmann, C. A. Ng, X. Trier and Z. Wang, An overview of the uses of per- and polyfluoroalkyl substances (PFAS), Environ. Sci.: Processes Impacts, 2020, DOI: 10.1039/d0em00291g.

7 I. T. Cousins, J. C. DeWitt, J. Glüge, G. Goldenman, D. Herzke, R. Lohmann, M. Miller, C. A. Ng, M. Scheringer, L. Vierke and Z. Wang, Strategies for grouping per- and polyfluoroalkyl substances (PFAS) to protect human and environmental health, Environ. Sci.: Processes Impacts, 2020, 22, 1444-1460.

8 ECHA, Restriction proposal for intentionally added microplastics in the EU - update. ECHA/NR/19/28, accessed: 08-05-2020, https://echa.europa.eu/de/-/ restriction-proposal-for-intentionally-added-microplasticsin-the-eu-update.

9 R. C. Buck, J. Franklin, U. Berger, J. M. Conder, I. T. Cousins, P. de Voogt, A. A. Jensen, K. Kannan, S. A. Mabury and S. P. J. van Leeuwen, Perfluoroalkyl and polyfluoroalkyl substances in the environment: terminology, classification, and origins, Integr. Environ. Assess. Manage., 2011, 7, 513541.

10 OECD/UNEP, Toward a new comprehensive global database of per- and polyfluoroalkyl substances (PFASs): Summary report on updating the OECD 2007 list of per- and polyfluoroalkyl substances (PFASs), Organisation for Economic Co-operation and Development, Portal for Per and Poly Fluorinated Chemicals, accessed: 12/10/2020, 2018, http:/www.oecd.org/chemicalsafety/portalperfluorinated-chemicals/.

11 US Environmental Protection Agency, EPA's per- and polyfluoroalkyl substances (PFAS) action plan, Washington, DC, 2019, cited 2020 January, available from: https:// www.epa.gov/sites/production/files/2019-02/documents/ pfas_action_plan_021319_508co.

12 PFAS|EPA, PFAS structures in DSSTox, update August 2020, https://comptox.epa.gov/dashboard/chemical_lists/ PFASSTRUCT, accessed: 10/10/2020.

13 A. J. Williams, C. M. Grulke, J. Edwards, A. D. McEachran, K. Mansouri, N. C. Baker, G. Patlewicz, I. Shah, J. F. Wambaugh, R. S. Judson and A. M. Richard, The CompTox Chemistry Dashboard: a community data resource for environmental chemistry, J. Cheminf., 2017, 9, 61.

14 M. S. Johnson, R. C. Buck, I. T. Cousins, C. P. Weis and S. E. Fenton, Estimating Environmental Hazard and Risks from Exposure to Per- and Polyfluoroalkyl Substances 
(PFAS): Outcome of a SETAC Focused Topic Meeting, Environ. Toxicol. Chem., 2020, DOI: 10.1002/etc.4784.

15 M. Neumann and I. Schliebner, Protecting the Sources of Our Drinking Water-ARe-vised Proposal for Implementing Criteria and an Assessment Procedure to IdentifyPersistent, Mobile and Toxic (PMT) and Very Persistent, Very Mobile (vPvM) Substances Registered Under REACH, German Environment Agency, Dessau-Rosslau, 2017, 16 pages, ISSN 2363-8273.

16 B. J. Henry, J. P. Carlin, J. A. Hammerschmidt, R. C. Buck, L. W. Buxton, H. Fiedler, J. Seed and O. Hernandez, A critical review of the application of polymer of low concern and regulatory criteria to fluoropolymers, Integr. Environ. Assess. Manage., 2018, 14, 316-334.

17 M. G. Costello, R. M. Flynn and J. G. Owens, Fluoroethers and Fluoroamines, Kirk-Othmer Encyclopedia of Chemical Technology, John Wiley \& Sons, 2004.

18 ATSDR Toxicological profile for Perfluoroalkyls, Draft for Public Comment, Atlanta, GA, U.S. Department of Health and Human Services, Public Health Service, 2018, Last updated: September 26, 2019, (accessed: 11-05-2020), https://www.atsdr.cdc.gov/ToxProfiles/tp.asp?

id $=1117$ \&tid $=237$.

19 Z. Y. Wang, J. C. DeWitt, C. P. Higgins and I. T. Cousins, A Never-Ending Story of Per- and Polyfluoroalkyl Substances (PFASs)?, Environ. Sci. Technol., 2017, 51, 2508-2518.

20 R. Lohmann, I. T. Cousins, J. C. DeWitt, J. Glüge, G. Goldenman, D. Herzke, A. B. Lindstrom, M. F. Miller, C. A. Ng, S. Patton, M. Scheringer, X. Trier and Z. Wang, Are fluoropolymers really of low concern for human and environmental health and separate from other PFAS?, Environ. Sci. Technol., 2020, 54(20), 12820-12828.

21 A. K. Jain, B. P. Briegleb, K. Minschwaner and D. J. Wuebbles, Radiative forcings and global warming potentials of 39 greenhouse gases, J. Geophys. Res.: Atmos., 2000, 105, 20773-20790.

22 W.-T. Tsai, Environmental implications of perfluorotributylamine-a potent greenhouse gas, Mitigation and Adaptation Strategies for Global Change, 2017, 22, 225-231.

23 G. B. Post, Human Health Risk Characterization: A States Perspective. Keynote presentation at the SETAC North America Focused Topic Meeting: Environmental Risk Assessment of PFAS, 12-15 August 2019, Durham, NC, USA, 2019, accessed: 04-08-2020, available at: https:// www.delawareriverkeeper.org/sites/default/files/Gloria\% 20Post_State\%20Perspectives_SETAC\%20PFAS.4.pdf.

24 J. S. Bowman, Fluorotechnology Is Critical to Modern Life: The FluoroCouncil Counterpoint to the Madrid Statement, Environ. Health Perspect., 2015, 123, A112-A113.

25 ACC Responds to Misleading PFAS Report, American Chemistry Council, June 30, 2020, Amercian Chemistry Matters: A Blog of the American Chemistry Council, accessed: 03-07-2020, https://blog.americanchemistry.com/ 2020/06/acc-responds-to-misleading-pfas-report/.

26 D. O'Hagan, Understanding organofluorine chemistry. An introduction to the C-F bond, Chem. Soc. Rev., 2008, 37, 308-319.
27 D. M. Lemal, Perspective on Fluorocarbon Chemistry, J. Org. Chem., 2004, 69, 1-11.

28 G. Leroy, M. Sana, C. Wilante and R. M. Nemba, Bonddissociation energies of organic compounds - A tentative rationalization based on the concept of stabilization energy, J. Mol. Struct., 1989, 198, 159-173.

29 M. Ignatyev, M. Seidel, W. Hierse, E. Montenegro, P. Kirsch and A. Bathe, Fluortenside, German Patent, Kind Code: A1, DE102006031143, MERCK PATENT GMBH (DE), 2008, accessed: 12/10/2020, https://www.freepatentsonline.com/ DE102006031143.html.

30 M. Peschka, N. Fichtner, W. Hierse, P. Kirsch, E. Montenegro, M. Seidel, R. D. Wilken and T. P. Knepper, Synthesis and analytical follow-up of the mineralization of a new fluorosurfactant prototype, Chemosphere, 2008, 72, 1534-1540.

31 S. Banerjee, J. Schmidt, Y. Talmon, H. Hori, T. Asai and B. Ameduri, A degradable fluorinated surfactant for emulsion polymerization of vinylidene fluoride, Chem. Commun., 2018, 54, 11399-11402.

32 E. Webster, D. Mackay and F. Wania, Evaluating environmental persistence, Environ. Toxicol. Chem., 1998, 17, 2148-2158.

33 M. S. McLachlan, H. Zou and T. Gouin, Using Benchmarking To Strengthen the Assessment of Persistence, Environ. Sci. Technol., 2017, 51, 4-11.

34 J. G. Allen, These toxic chemicals are everywhere - even in your body. And they won't ever go away, "Opinions" article published in the Washington Post on 02-01-2018, accessed: 06-08-2020, available online at: https:// www.washingtonpost.com/opinions/these-toxic-chemicalsare-everywhere-and-they-wont-ever-go-away/2018/01/02/ 82e7e48a-e4ee-11e7-a65d-1ac0fd7f097e_story.html.

35 ECHA, European Chemicals Agency, Management of PBT/ vPvB substances under REACH, accessed: 11-02-2020, https://echa.europa.eu/management-of-pbt-vpvbsubstances.

36 I. T. Cousins, C. A. Ng, Z. Y. Wang and M. Scheringer, Why is high persistence alone a major cause of concern?, Environ. Sci. Process. Impacts, 2019, 21, 781-792.

37 US EPA, PFAS Chemical Lists and Tiered Testing Methods Descriptions, accessed: 28-04-2020, https:/www.epa.gov/ chemical-research/pfas-chemical-lists-and-tiered-testingmethods-descriptions.

38 S. Jensen, The PCB Story, Ambio, 1972, 1, 123-131.

39 M. E. Stephenson, An approach to the identification of organic compounds hazardous to the environment and human health, Ecotoxicol. Environ. Saf., 1977, 1, 39-48.

40 Europen Environmental Agency (EEA), Late Lessons from Early Warnings: The Precautionary Principle 1896-2000, ed. P. Harremoës, D. Gee, M. MacGarvin, A. Stirling, J. Keys, B. Wynne and S. Guedes Vaz, EEA, Copenhagen, 2001, ISBN 92-9167-323-4.

41 L. M. Persson, M. Breitholtz, I. T. Cousins, C. A. de Wit, M. MacLeod and M. S. McLachlan, Confronting Unknown Planetary Boundary Threats from Chemical Pollution, Environ. Sci. Technol., 2013, 47, 12619-12622. 
42 M. MacLeod, M. Breitholtz, I. T. Cousins, C. A. d. Wit, L. M. Persson, C. Rudén and M. S. McLachlan, Identifying Chemicals That Are Planetary Boundary Threats, Environ. Sci. Technol., 2014, 48, 11057-11063.

43 J. Rockström, W. Steffen, K. Noone, Å. Persson, F. S. Chapin, E. F. Lambin, T. M. Lenton, M. Scheffer, C. Folke, H. J. Schellnhuber, B. Nykvist, C. A. de Wit, T. Hughes, S. van der Leeuw, H. Rodhe, S. Sörlin, P. K. Snyder, R. Costanza, U. Svedin, M. Falkenmark, L. Karlberg, R. W. Corell, V. J. Fabry, J. Hansen, B. Walker, D. Liverman, K. Richardson, P. Crutzen and J. A. Foley, A safe operating space for humanity, Nature, 2009, 461, 472475.

44 M. S. McLachlan, Can the Stockholm convention address the spectrum of chemicals currently under regulatory scrutiny? Advocating a more prominent role for modeling in POP screening assessment, Environ. Sci.: Processes Impacts, 2018, 20, 32-37.

45 I. T. Cousins, R. Vestergren, Z. Y. Wang, M. Scheringer and M. S. McLachlan, The precautionary principle and chemicals management: The example of perfluoroalkyl acids in groundwater, Environ. Int., 2016, 94, 331-340.

46 M. C. Walker and M. C. Y. Chang, Natural and engineered biosynthesis of fluorinated natural products, Chem. Soc. Rev., 2014, 43, 6527-6536.

47 B. F. Scott, R. W. Macdonald, K. Kannan, A. Fisk, A. Witter, N. Yamashita, L. Durham, C. Spencer and D. C. G. Muir, Trifluoroacetate profiles in the Arctic, Atlantic, and Pacific Oceans, Environ. Sci. Technol., 2005, 39, 6555-6560.

48 P. T. Anastas and J. C. Warner, Green Chemistry: Theory and Practice, Oxford University Press, New York, NY, 1998.
49 W. McDonough and M. Braungart, Cradle to Cradle: Remaking the Way We Make Things, New York, North Point Press, 2002, ISBN 0865475873.

50 I. T. Cousins, G. Goldenman, D. Herzke, R. Lohmann, M. Miller, C. A. Ng, S. Patton, M. Scheringer, X. Trier, L. Vierke, Z. Wang and J. C. DeWitt, The concept of essential use for determining when uses of PFASs can be phased out, Environ. Sci. Process. Impacts, 2019, 21, 18031815.

51 EPA South Australia, Per- and poly-fluoroalkyl substances (PFAS): Transitioning to fluorine-free firefighting foam, accessed: 17-02-2020, https://www.epa.sa.gov.au/ environmental_info/perfluorinated-compounds.

52 H. Holmquist, S. Schellenberger, I. van der Veen, G. M. Peters, P. E. G. Leonards and I. T. Cousins, Properties, performance and associated hazards of state-ofthe-art durable water repellent (DWR) chemistry for textile finishing, Environ. Int., 2016, 91, 251-264.

53 FIS Moves to Ban Fluorinated Ski Waxes for the 2020/2021 Season, accessed: 17-02-2020, https://fasterskier.com/ fsarticle/fis-moves-to-ban-fluorinated-ski-waxes-for-the2020-2021-season/.

54 ChemSec. Interrnational Chemicals Secretariat, News Article from 11-07-18. The world's biggest cosmetics brands say NO to PFCs, accessed: 11-05-2020, https://chemsec.org/theworlds-biggest-cosmetics-brands-say-no-to-pfcs/.

55 Food Packaging Forum, News: Denmark to ban PFAS in paper \& board in 2020, accessed: 17-02-2020, https:// www.foodpackagingforum.org/news/denmark-to-ban-pfasin-paper-board-in-2020. 